\title{
Green synthesis of gold nanoparticles using marine algae and evaluation of their catalytic activity
}

\author{
M. Ramakrishna ${ }^{1}$ Dandamudi Rajesh Babu ${ }^{1} \cdot$ R. M. Gengan ${ }^{2} \cdot$ S. Chandra ${ }^{3}$. \\ G. Nageswara Rao ${ }^{1}$
}

Received: 28 May 2015/Accepted: 6 August 2015/Published online: 23 October 2015

(c) The Author(s) 2015. This article is published with open access at Springerlink.com

\begin{abstract}
The hazardous effects of current nanoparticle synthesis methods have steered researchers to focus on developing newer eco-friendly methods for synthesizing nanoparticles using non-toxic chemicals. Owing to the diverse applications of nanoparticles in various fields such as catalysis, medicine, diagnostics, and sensors, several novel green approaches have been explored for synthesizing nanoparticles using different natural sources such as plants, algae, bacteria, and fungi. Hence, in the present work, a green method for the synthesis of gold nanoparticles (AuNPs) under ambient conditions using aqueous
\end{abstract}

G. Nageswara Rao

gnageswararao@sssihl.edu.in

M. Ramakrishna

mramakrishna@sssihl.edu.in

Dandamudi Rajesh Babu

drajeshbabu@sssihl.edu.in

R. M. Gengan

genganrm@dut.ac.za

S. Chandra

chan1958@gmail.com

1 Department of Chemistry, Sri Sathya Sai Institute of Higher Learning, Prasanthinilayam,

Puttaparthi 515134, Andhra Pradesh, India

2 Chemistry Department, Durban University of Technology, Durban 4001, South Africa

3 LN Government College, Ponneri 601204, Tamil Nadu, India extracts of marine brown algae is reported and the synthesized AuNPs were evaluated for their catalytic efficiency. The aqueous extracts of algae comprise reducing as well as capping agents required for the formation of AuNPs. The Fourier transform infrared spectra of the extracts revealed the presence of compounds having hydroxyl groups that are largely responsible for the reduction of auric chloride to AuNPs at room temperature. Results from high-resolution transmission electron microscopy and dynamic light scattering studies suggested that most of the biosynthesized AuNPs are nearly spherical in shape with an average size in the range of $27-35 \mathrm{~nm}$. High negative values of zeta potential measurement confirmed the stability of AuNPs. Moreover, the reduction kinetics of AuNPs studied by UV-visible spectrophotometry showed that they have good catalytic efficiency in the degradation of dyes as well as reduction of nitro compounds in the presence of sodium borohydride as reducing agent. This simple process for the biosynthesis of gold nanoparticles is rapid, cost-effective and eco-friendly. The formation of AuNPs was observed with the change of pale yellow gold solution to ruby red color of gold nanoparticles and confirmed by surface plasmon spectra using UV-visible spectroscopy. Nanoparticles synthesized through such environmentally benign routes can be used for synthesizing many other metal nanoparticles as well as for a wide range of biomedical applications, for commercial production on a large scale and also can be used as efficient catalysts for different organic reactions. 


\section{Graphical abstract}

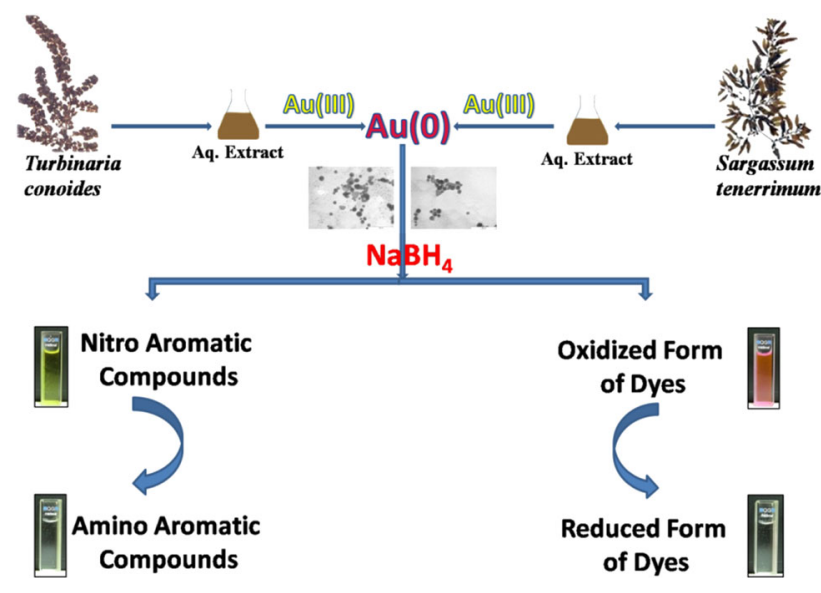

Keywords Green synthesis - Turbinaria conoides . Sargassum tenerrimum · Gold nanoparticles · Catalysis

\section{Introduction}

Nanoparticles are gaining enormous research attention in various fields such as chemistry, physics, materials science, life sciences and engineering. This high interest in nanoparticles is because of their unique optical, magnetic, electronic and catalytic properties with their distinctive feature of size and shape [1, 2]. Many of the existing physical and chemical methods suffer from few drawbacks such as high cost, use of environmentally hazardous chemicals and non-availability for medical applications due to presence of toxic capping agents [3, 4]. These factors contributed towards exploration of new methods and materials for the production of nanoparticles based on the principles of "Green Chemistry". The emphasis in this approach is on the synthesis and application of the nanoparticles for a maximum societal benefit, with minimal impact on the ecosystem [5]. As both the synthesis and applications of nanoparticles are important, many researchers from both academic and industry are focusing towards biological systems such as plants, marine algae, fungi and bacteria for the production of nanoparticles [69]. The compounds present in the extracts can act as reducing as well as stabilizing agents and render more biocompatibility to biosynthesized nanoparticles [10].

Oceans are a rich source for many varieties of natural products. Seaweeds are one such variety that belongs to a group of plants known as marine algae [11]. Seaweeds are considered as a source of bioactive compounds such as proteins, lipids, carbohydrates, carotenoids, vitamins and many other secondary metabolites with a wide range of biological activities [12-14]. Few algae such as
Acanthophora spicifera [15], Chlorella pyrenoidusa [16], Kappaphycus alvarezii [17], Sargassum wightii [18], Sargassum myriocystum [19], Stoechospermum marginatum [20] and Laminaria japonica [21] have been used for the synthesis of stable and polydispersed gold nanoparticles. The biosynthesized nanoparticles are even tested for their bacterial pathogenicity and other biological activities. Thus, algae stand as a prospective material for green synthesis of nanoparticles. One of the promising applications of gold nanoparticles (AuNPs) is in the area of catalysis and AuNPs can act as excellent catalysts for many organic reactions even at ambient temperatures. This unique property led many researchers to study the catalytic efficiency of gold nanoparticles. Aromatic nitrocompounds are one of the most commonly used chemical groups in the manufacturing industry and are extremely hazardous if released in environment. However, the reduced products of these aromatic nitro compounds are largely used in preparation of polymers, rubber products, hair dyes, as intermediates for drugs in pharmaceutical industry, etc. [22]. AuNPs act as efficient catalysts for this reduction process. Owing to the toxic effects as well as undesirable by product formation in the reaction medium, the chemically synthesized AuNPs are not suitable as catalysts for many industrial applications despite exhibiting high catalytic activity. Hence, there exists a boundless necessity to develop efficient catalysts through alternate methods for this chemical reduction which is very essential for beneficial applications. One of the major sources of environmental contamination is through dyes from the textile, paint, and paper manufacturing industries [23, 24]. Dyes belonging to the family of xanthines such as Rhodamine B, and Sulforhodamine are extremely harmful because of their severe ecological impact and are non-biodegradable. These dyes should be treated before discharging into the environment. Many physical, chemical treatment methods and biotransformation agents are being used for the reduction of these pollutants. But these are highly ineffective, do not totally eliminate and also involve high operational costs [25]. Hence, there is a need to develop inexpensive methods which degrade the dye molecules into non-toxic compounds.

In this regard, we report the synthesis of AuNPs using aqueous extracts of two brown algae Turbinaria conoides and Sargassum tenerrimum. The reported nanoparticles synthesis is very simple, efficient and economical. Though there are many reports on biosynthesis of AuNPs from natural sources, application-based reports are few and so we evaluated the biosynthesized AuNPs for their catalytic efficiency using nitro compounds and dyes as model substrates for decolorization. The AuNPs are characterized by UV-visible spectroscopy, high-resolution transmission electron microscopy (HRTEM), Fourier transform infrared 
(FTIR) and dynamic light scattering (DLS) with Zeta potential measurements.

\section{Results and discussion}

\section{Biosynthesis of gold nanoparticles and UV-vis spectroscopy}

Aqueous extracts of $T$. conoides and $S$. tenerrimum were added into two separate flasks containing gold solution. The formation of AuNPs was confirmed by the development of ruby red or pinkish color which is a characteristic of AuNPs [26]. The color change from light yellow to ruby red or pinkish red is due to the excitation of surface plasmon resonance (SPR) in the gold nanoparticles induced by passing light and this observation was confirmed by UVvis spectral analysis [11]. Change in the SPR of AuNPs with respect to reaction time can be seen in Fig. 1. Intensity of the color as well as the absorbance values increased gradually in the reaction medium along with the reaction time which implied an increasing AuNPs concentration and indicated continuous reduction of gold ions. AuNPs from T. conoides (Fig. 1a) showed a weak SPR band at $536 \mathrm{~nm}$ and after $90 \mathrm{~min}$, a red shift was observed in SPR at $540 \mathrm{~nm}$ due to slight modification in the size and shape of AuNPs. Absorption spectra of AuNPs synthesized from $S$. tenerrimum are shown in Fig. 1b. The bioreduction of $\mathrm{Au}(\mathrm{III})$ ions and formation of AuNPs is confirmed by the gradual appearance of pinkish red color. A weak SPR band at $525 \mathrm{~nm}$ can be seen in Fig. $1 \mathrm{~b}$ and after $60 \mathrm{~min}$, a red shift to $547 \mathrm{~nm}$ was observed due to the formation of AuNPs. A gradual increase in the absorption intensity and saturation at absorbance value 2.069 indicate the complete reduction of gold ions in the reaction medium. The incubation period of 15 days did not show any considerable change in SPR intensity of $T$. conoides thereby ascertaining the stability of biosynthesized nanoparticles. However, with respect to $S$. tenerrimum, there was a slight decrease in the absorption intensity of AuNPs and broadening of SPR after an incubation period of 15 days. In Fig. 1, the absorbance around $520-560 \mathrm{~nm}$ is due to the SPR exhibited by spherical nanoparticles. However, the spectral pattern in the near infrared (NIR) region shows a shoulder band around $750 \mathrm{~nm}$ which increased along with reaction time, thereby indicating that the biosynthesized AuNPs are also anisotropic in nature which is confirmed by TEM images. The biosynthesized AuNPs relatively show a sharper absorbance peak around $540 \mathrm{~nm}$ and a broader peak between 700 and $800 \mathrm{~nm}$ in Fig. 1b. Brown algal cell walls are rich in polysaccharides and so have abundant hydroxyl groups. Results from Mata et al. [27] confirmed the participation of hydroxyl groups during biosynthesis of AuNPs using Fucus vesiculosus. Fucoxanthins which are carotenoids rich in hydroxyl groups and are algal pigments can also contribute with respect to gold reduction as these have good reducing properties [28]. Fucoidans refer to a type of polysaccharide which contains considerable percentages of L-fucose and sulfate ester groups [29]. Results from [ [30], [31] ] show that T. conoides has higher fucose content than $S$. tenerrimum. Hence, this may be the result for a faster formation of AuNPs in T. conoides. The plasmon absorption of AuNPs is dependent on particle size and nature of the nanoparticles can be qualitatively related to the shape of the resonance peak [32]. Sharp absorbance peaks are exhibited by small and uniform sized nanoparticles, whereas broad absorbance peaks imply a wider size distribution or aggregation of nanoparticles [33]. According to Mie's theory, spherical AuNPs exhibit strong absorption at $520 \mathrm{~nm}$ without any additional band;
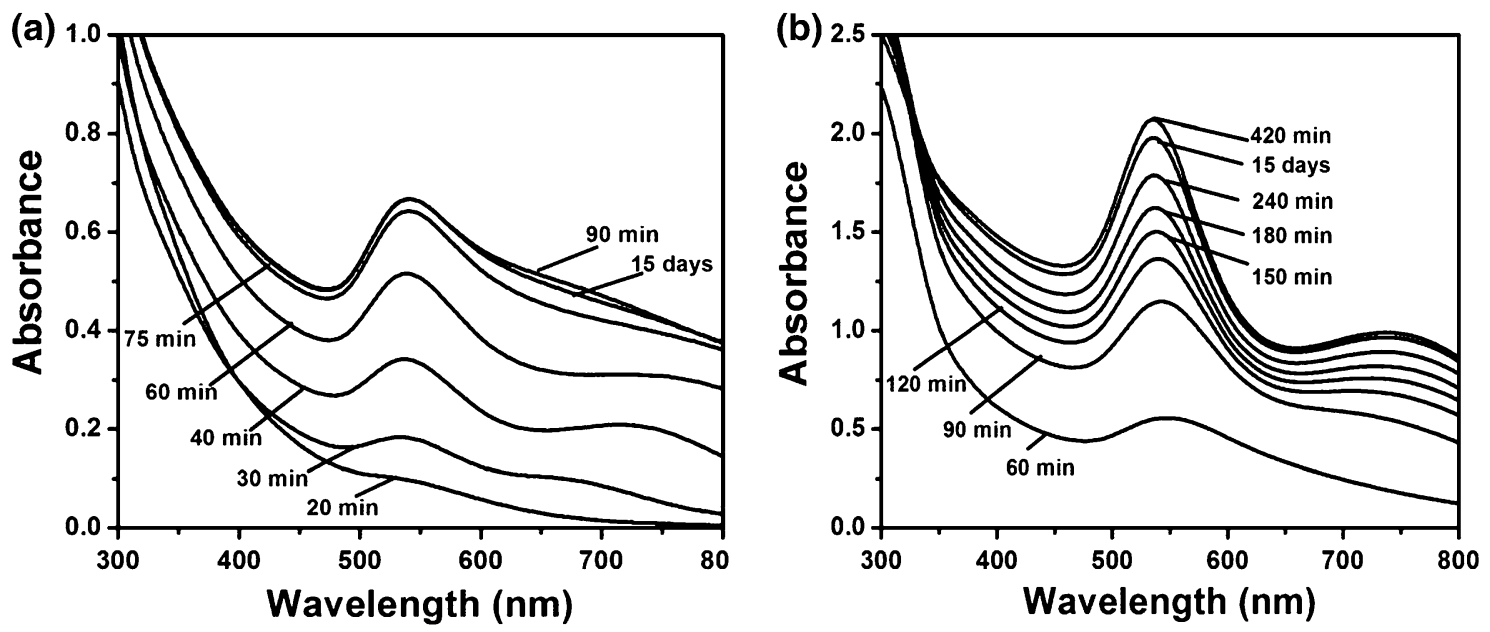

Fig. 1 UV-vis absorption spectra of time-dependent formation of AuNPs synthesized from a Turbinaria conoides and b Sargassum tenerrimum 
however, the triangular shape AuNPs absorb at $540 \mathrm{~nm}$ along with additional absorption in near infrared region. Anisotropic AuNPs give rise to more than one SPR band depending on the shape of the particle. The number of SPR peaks and the symmetry of nanoparticles are inversely proportional to each other i.e., as the number of SPR peaks increases, the symmetry of nanoparticles decreases [34]. Thus, spherical, triangular and other shaped AuNPs show one, two or more SPR peaks. Results from the present study show the presence of isotropic and anisotropic AuNPs as can be seen in Fig. 1 with two SPR bands. Anisotropic AuNPs have their characteristic absorbance in the NIR region and also they are more compatible for usage in many biological applications [35].

\section{Fourier transform infrared (FTIR) studies}

FTIR spectral measurements on aqueous extracts of marine algae and the obtained AuNPs are carried out to identify the possible biomolecules that are responsible for the reduction of $\mathrm{Au}(\mathrm{III})$ ions as well as capping of the AuNPs. Figure 2a shows IR spectra of the aqueous extract of $T$. conoides with many prominent peaks containing diverse
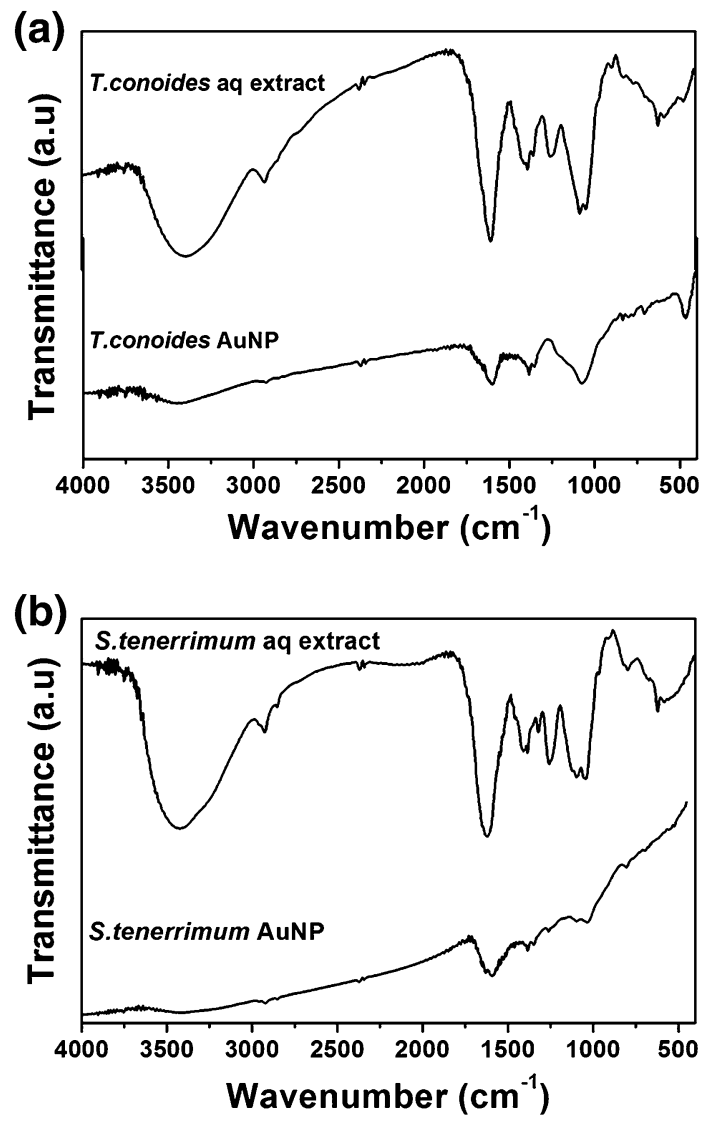

Fig. 2 FTIR spectra of a T. conoides aqueous extract and its AuNPs, b $S$. tenerrimum aqueous extract and its AuNPs functional groups. Polysaccharides are rich in brown algae and so they have abundant hydroxyl groups. The broad peak around $3385 \mathrm{~cm}^{-1}$ in the IR spectra of aqueous extract of $T$. conoides corresponds to the existence of both $-\mathrm{NH}_{2}$ and $-\mathrm{OH}$ groups. This broadness is due to the overlap of both $\mathrm{O}-\mathrm{H}$ bond stretching of high concentration of alcohols or phenols and also the $\mathrm{N}-\mathrm{H}$ stretch of $1^{\circ}$ amines. T. conoides is rich in polyphenolic substances [36, 37] and phytochemical investigation led to the isolation of sulfated polysaccharides [30, 38]. The presence of carboxyl groups on the surface of $T$. conoides as reported earlier [39] is confirmed by the presence of a strong band at $1602 \mathrm{~cm}^{-1}$ and a weak band around $1400 \mathrm{~cm}^{-1}$ due to the asymmetrical and symmetrical stretching of carboxylate ions. The peak at $1253 \mathrm{~cm}^{-1}$ denotes $\mathrm{C}-\mathrm{N}$ stretching of aliphatic amines. The peaks at 1078 and $1043 \mathrm{~cm}^{-1}$ are due to the $\mathrm{C}-\mathrm{N}$ stretching vibrations of aliphatic amines present in the algae. IR spectra of AuNPs in Fig. 2a showed weaker bands around 3385, $1602 \mathrm{~cm}^{-1}$ and suppressed band at $1253 \mathrm{~cm}^{-1}$ than compared with the extract. This observation revealed that compounds having amine and hydroxyl functional groups could possibly be associated in the reduction as well as stabilization of AuNPs which is in agreement with studies reported earlier [28, 40].

IR spectra of the aqueous extract of $S$. tenerrimum are shown in Fig. $2 \mathrm{~b}$ and previously reported studies showed the presence of various secondary metabolites such as amino acids, alkaloids, carbohydrates, flavonoids, saponins, sterols, tannins, proteins and phenolic acids from $S$. tenerrimum [41]. The presence of an absorption band at $3446 \mathrm{~cm}^{-1}$ is due to the $\mathrm{N}-\mathrm{H}$ stretching vibrations of peptide linkages and $\mathrm{O}-\mathrm{H}$ stretch vibrations of phenolic $\mathrm{OH}$ groups indicating the existence of polyphenols and phenolic acids. Peaks at 1610 and $1420 \mathrm{~cm}^{-1}$ are characteristic of $\mathrm{COO}^{-}$stretching of alginates [42]. The peak at $1321 \mathrm{~cm}^{-1}$ is due to $\mathrm{C}-\mathrm{N}$ stretch of amine groups. It can be observed from Fig. 2 that FTIR spectra of aqueous extracts of both the species of algae appear almost similar and there exist some common absorption peaks. IR spectra for AuNPs synthesized from $T$. conoides look similar to that of the crude extract with a slight variation in the intensities and wavelengths. The peak at $3447 \mathrm{~cm}^{-1}$ has been shifted from $3385 \mathrm{~cm}^{-1}$ after reducing the chloroauric acid which indicates the capping with gold nanoparticles. Similarly, IR spectra in case of $S$. tenerrimum too show a large variation of intensity at $3446 \mathrm{~cm}^{-1}$ and almost similar absorption bands with that of the extract. Previous studies have shown that the hydroxyl groups have a stronger ability to interact with nanoparticles and therefore the secondary metabolites containing hydroxyl group may act as capping agents for the formation of stable gold nanoparticles [28, 43]. Both the brown algae studied are rich in polysaccharides [30, 31, 44] and these may be responsible for the formation of 
stable gold nanoparticles. Also, it is apparent from Fig. 2 that the presence of different secondary metabolites with various functional groups in the aqueous extracts may act as reducing as well as capping agents for AuNPs.

\section{High-resolution transmission electron microscopy}

Figure 3 shows representative TEM images and the corresponding size distribution histograms of AuNPs synthesized from the aqueous extracts of $T$. conoides and $S$. tenerrimum. As shown in Fig. 3a, AuNPs synthesized from T. conoides are anisotropic. The AuNPs formed are polydisperse and shape disparity can be seen. Inset of Fig. 3a shows that the diameters of AuNPs vary from approximately 12 to $57 \mathrm{~nm}$ with average size of around $27.5 \mathrm{~nm}$. Figure $3 \mathrm{~b}$ shows the TEM image of AuNPs synthesized from $S$. tenerrimum. Inset of Fig. $3 \mathrm{~b}$ indicates the AuNPs that have diameters ranging from approximately 5 to $45 \mathrm{~nm}$ and the average particles size is around $35 \mathrm{~nm}$. From Fig. 3, we observe a variation in particle size and AuNPs that are anisotropic. The effect of reducing agent ratio has been varied and the ratio of 4.5:0.5 (extract:gold solution) was found to produce stable AuNPs than other variations which gave fewer as well as unstable AuNPs.

\section{Dynamic light scattering (DLS) and zeta potential studies}

DLS has been used to measure the particle sizes in colloidal solution and the size distribution data of AuNPs obtained at $\mathrm{pH} 7$ from $T$. conoides and S. tenerrimum are shown in Fig. 4a, b. DLS analysis indicated that the hydrodynamic radius is $28.60 \pm 20.65$ ( $Z$-average $\pm(\mathrm{SD}$ ) $\mathrm{d} \mathrm{nm}$ ) for the AuNPs synthesized from $T$. conoides with a polydispersity index of 0.521 . The corresponding zeta potential and zeta deviation values are -26.3 and $27.5 \mathrm{mV}$. The average particle size distribution is $82.30 \pm 52.82$ ( $Z$ - average $\pm(\mathrm{SD}) \mathrm{d} \mathrm{nm}$ ) for nanoparticles synthesized from $S$. tenerrimum with a polydispersity index of 0.412 . The zeta potential and zeta deviation values obtained are -29.1 and $82.8 \mathrm{mV}$, respectively. Both the zeta potential values obtained imply a stable dispersion of the biosynthesized AuNPs. A zeta potential higher than $30 \mathrm{mV}$ or lesser than $-30 \mathrm{mV}$ is indicative of a stable system [3]. The large negative potential value suggests the presence of negatively charged moieties in the extracts that confer electrostatic stability to the nanoparticles.

\section{Catalytic activity of the biosynthesized gold nanoparticles}

\section{Reduction of nitro compounds (4-nitrophenol and p-nitroaniline)}

To study the catalytic activity of the biosynthesized gold nanoparticles, we have chosen the reduction of nitroarenes (4-nitrophenol and $p$-nitroaniline) to their corresponding aminoarenes (4-aminophenol and $p$-phenylenediamine). Progress of the reduction reaction was visualized with discoloration of characteristic yellow color of the nitro compounds and the reaction was monitored with UV-vis spectroscopy as shown in Fig. 5.

The maximum absorbance of aqueous solution of 4-nitrophenol (4-NP) was found to be at $317 \mathrm{~nm}$ and the addition of $\mathrm{NaBH}_{4}$ caused a red shift in the absorbance from 317 to $400 \mathrm{~nm}$. This is due to the formation of 4-nitrophenolate ion and is indicative due to the color change from light yellow to intense yellow. The absorption peak at $400 \mathrm{~nm}$ remained unaltered with time in the absence of nanoparticles, suggesting that the reduction did not take place. But with the addition of nanoparticles synthesized from the aqueous extract of $T$. conoides, the yellow color faded gradually to a colorless solution. The intensity of the absorption peak at $400 \mathrm{~nm}$ decreased
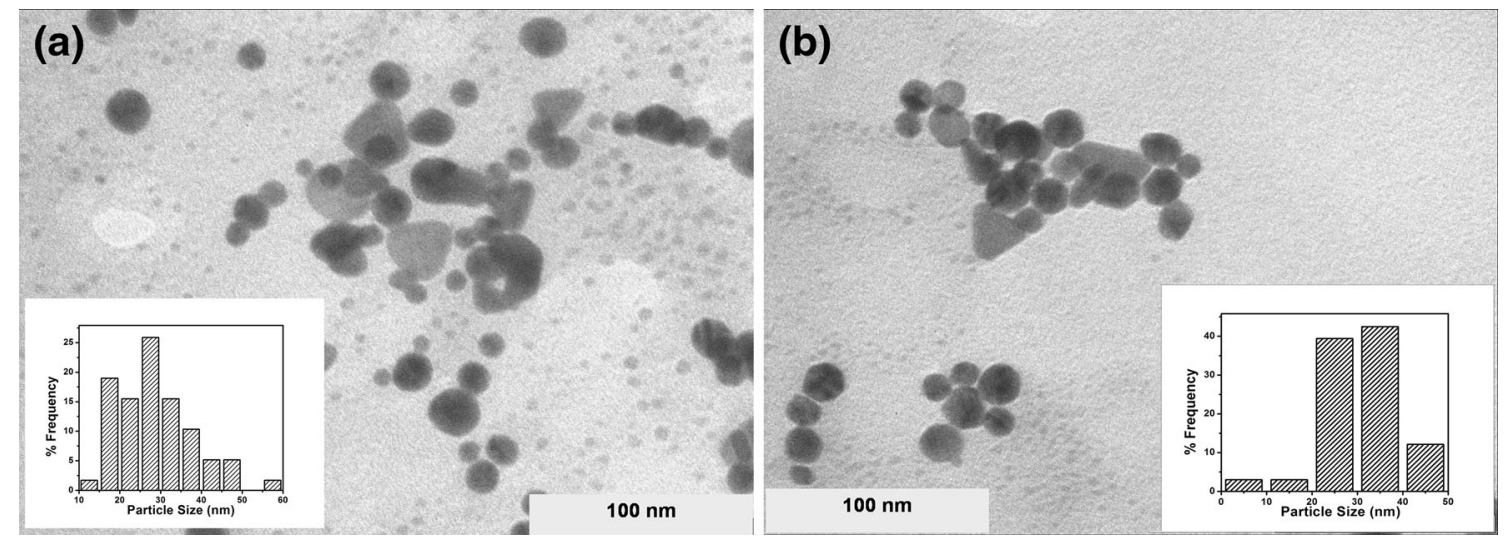

Fig. 3 HRTEM and particle size distribution histogram (inset) of AuNPs synthesized from a T. conoides and b S. tenerrimum 
(a)

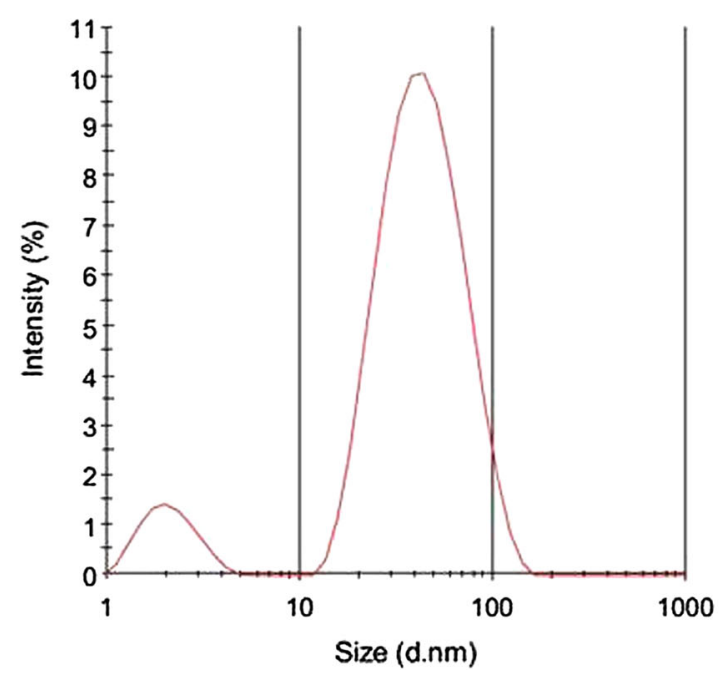

(b)

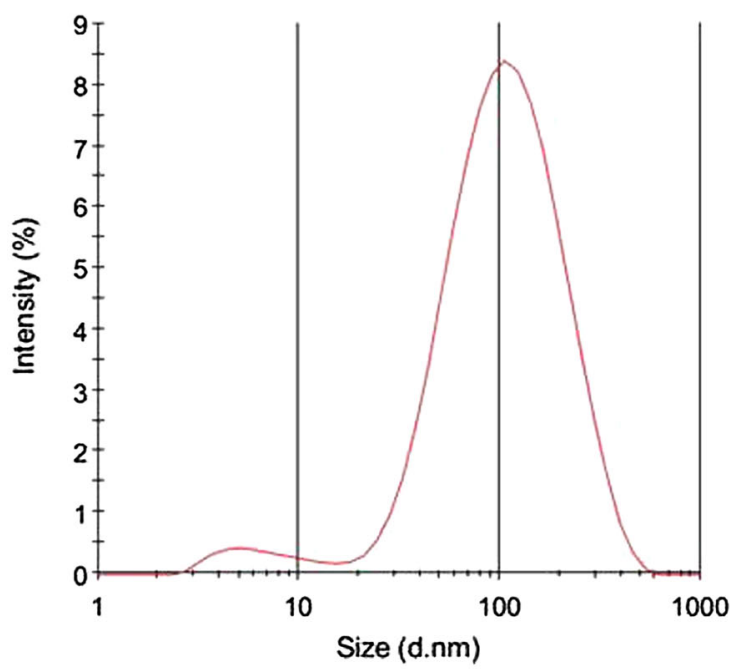

Fig. 4 Size distribution of AuNPs synthesized from a T. conoides and b S. tenerrimum

(a)
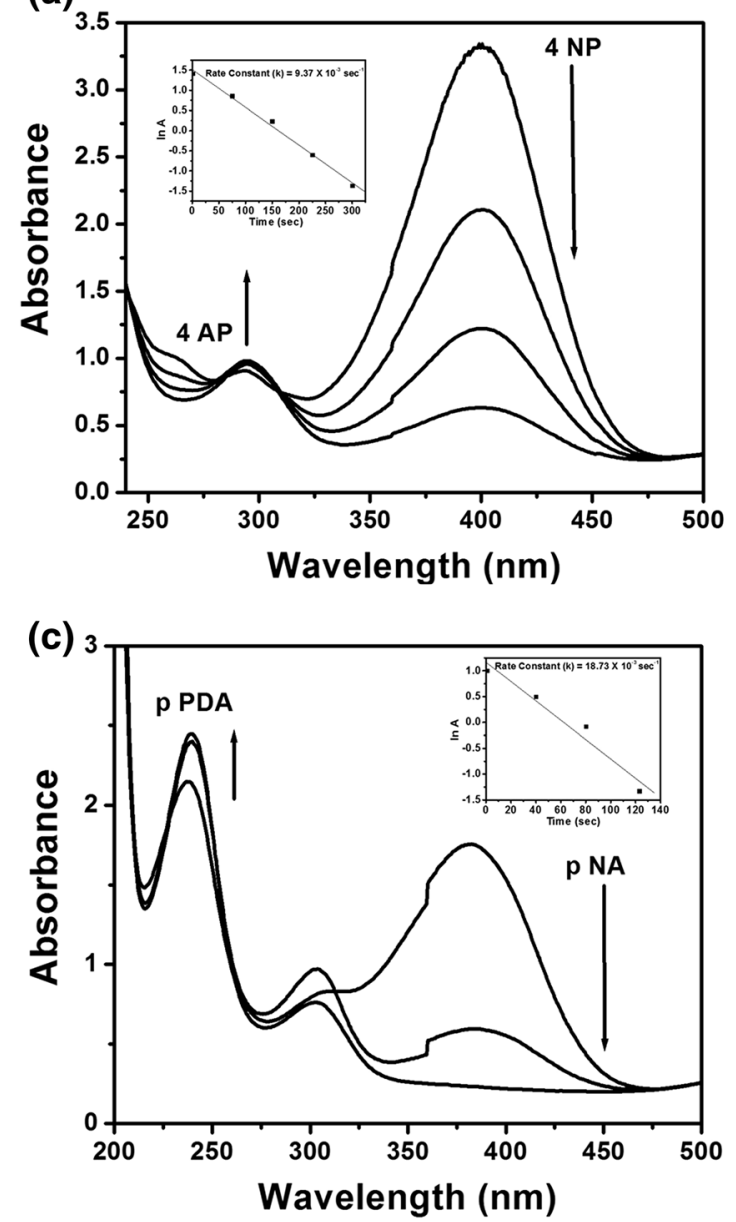

Fig. 5 Time-dependent UV-vis spectra of the borohydride reduction of 4-NP and $p$-NA catalyzed by AuNPs obtained from T. conoides (a, c) and $S$. tenerrimum (b, d). Inset graphs are the corresponding
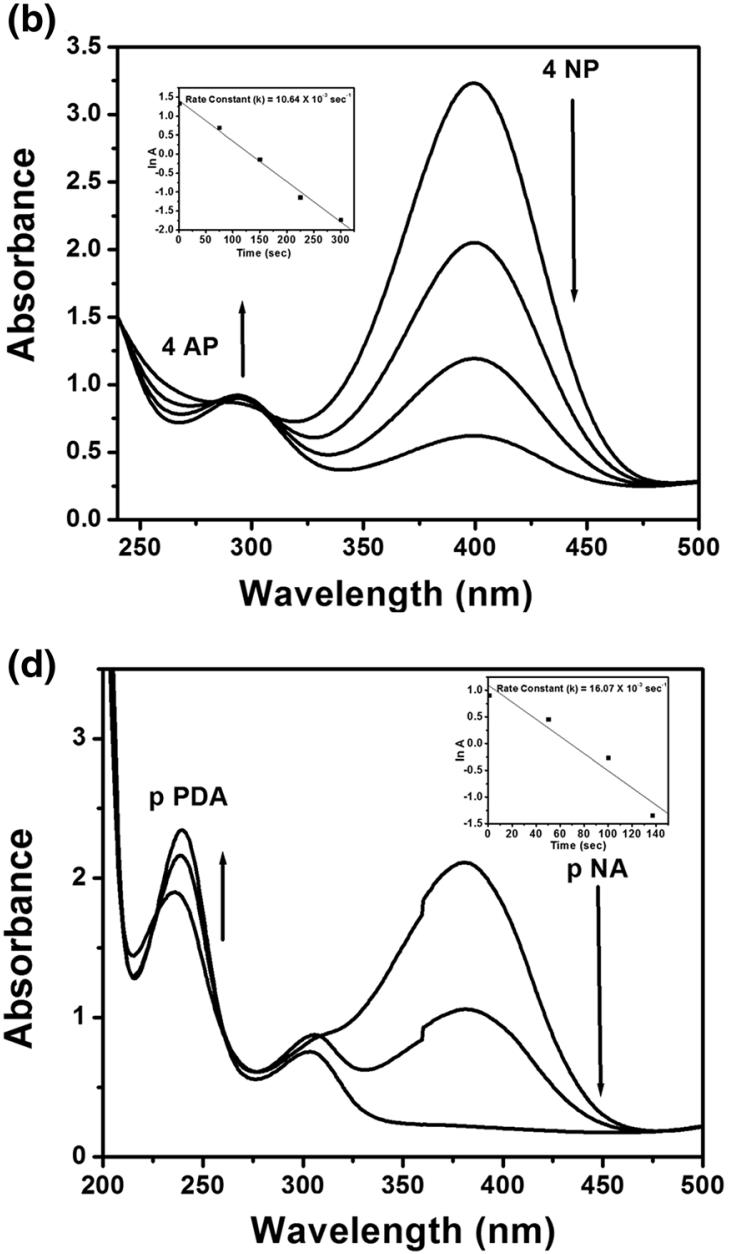

kinetic plots of $\ln A$ ( $A=$ absorbance of 4-nitrophenolate ion at $400 \mathrm{~nm}$ ) versus time 
gradually with the concomitant appearance of a new peak at $298 \mathrm{~nm}$, corresponding to the formation of 4-aminophenol (4-AP) (Fig. 5a) [45]. In this process of catalytic reduction, the nanoparticles transfer the electrons from $\mathrm{BH}_{4}{ }^{-}$ions to nitro compound, which was qualitatively monitored by UV-vis spectrophotometer. As seen in Fig. 5a, the presence of isosbestic points indicates that 4-NP is fully converted to only 4-AP and no side reaction took place [46]. The reaction was complete within $300 \mathrm{~s}$ at room temperature. Inset of Fig. 5a shows that the logarithm of the absorbance of 4-nitrophenolate at $400 \mathrm{~nm}(\ln A)$ versus time showed a good linear correlation and the rate constant $(k)$ was calculated to be $9.37 \times 10^{-3} \mathrm{~s}^{-1}$. Furthermore, the same method was followed for evaluating the catalytic effect of AuNPs obtained from S. tenerrimum. The reaction was complete within $300 \mathrm{~s}$ and $k$ value was determined to be $10.64 \times 10^{-3} \mathrm{~s}^{-1}$ (Fig. 5b).

The catalytic efficiency of the AuNPs obtained from both the species of algae was also examined for the reduction of $p$-nitroaniline ( $p$-NA) in the presence of $\mathrm{NaBH}_{4}$. The absorption spectrum of a mixture of $p$-NA and $\mathrm{NaBH}_{4}$ has shown a band at $380 \mathrm{~nm}$. However, with the addition of AuNPs to the reaction mixture, the band at $380 \mathrm{~nm}$ decreased gradually, whereas a new band at $238 \mathrm{~nm}$ evolved gradually due to the formation of the reaction product $p$-phenylenediamine ( $p$-PDA) in the solution (Fig. 5c, d). Initially, the $p$-NA molecules are adsorbed on the surface of the gold nanoparticles which play an important role in the electron transfer process. The electron transfer occurs from the negatively charged $\mathrm{BH}_{4}{ }^{-}$ to the $p$-NA via the AuNPs. The $p$-NA is then reduced to $p$ PDA. This has been observed by the slow disappearance of the characteristic yellow color of $p$-NA into colorless solution due to successful reduction reaction. The complete decolorization has been observed within $123 \mathrm{~s}$ in case of AuNPs synthesized from T. conoides and within $140 \mathrm{~s}$ with AuNPs synthesized from $S$. tenerrimum. The reaction rates have been calculated by taking the logarithm values (ln $A$ ) of absorbance at $380 \mathrm{~nm}$ with respect to time and the plots showed a good linear correlation. The $k$ values for this catalytic conversion of $p$-NA to $p$-PDA were calculated to be $18.73 \times 10^{-3} \mathrm{~s}^{-1}$ for AuNPs synthesized from T. conoides (Fig. 5c) and $16.07 \times 10^{-3} \mathrm{~s}^{-1}$ for AuNPs synthesized from S. tenerrimum (Fig. 5d).

For the above reduction reactions, control experiments have been performed by taking water instead of nanoparticles solution. The yellow color of the nitro compounds solution has not changed which confirmed the catalytic role of nanoparticles. The concentration of $\mathrm{NaBH}_{4}$ used in the reaction mixture is very much higher than the concentration of the nitro compounds. It is assumed that the concentration of $\mathrm{NaBH}_{4}$ remains constant during the reaction and the reduction rate can be assumed to be independent of
$\mathrm{NaBH}_{4}$ concentration. In this context, the order of the reactions is considered to be a pseudo-first-order reaction. Results from present study showed better catalytic efficiency than previously reported studies under similar conditions. Biogenic AuNPs obtained from Breynia rhamnoides were evaluated for reduction of 4-NP [47] and the $k$ value obtained was $7.66 \times 10^{-3} \mathrm{~s}^{-1}$ which is lesser than the values obtained for 4-NP reduction in the present study. The $k$ values obtained for 4-NP reduction using poly(amidoamine) dendrimer-metal nanocomposites (silver, platinum, palladium) of different generations exhibited catalytic rates in the range $0.0263 \times 10^{-3} \mathrm{~s}^{-1}$ to $3.59 \times 10^{-3} \mathrm{~s}^{-1}$ [48] were lower than the results obtained in the present study with respect to reduction of 4-NP. Results from the present study when compared with previous works are more promising for further application of AuNPs. Both 4-AP and $p$-PDA are very useful, and important as they are widely used as intermediates in organic synthesis. They are also used for preparing dyes such as azo dyes, sulfur dyes and fur dyes. 4-AP is used in the production of medicines such as paracetamol and clofibrate. $p$-PDA is also used in the manufacture of polymers, rubber antioxidants and as photo developer material [49]. The conventional methods for synthesizing aminobenzenes such as 4-AP and $p$-PDA suffer from the limitations of rigorous reaction conditions, high costs and tedious procedures. Thus, the above method is a green, simple and highly efficient one for preparing gold nanoparticles as the results are encouraging compared to those reported from the literature.

\section{Reduction of organic dye molecules (Rhodamine B and Sulforhodamine 101)}

The characteristic absorption peak occurs at $553 \mathrm{~nm}$ for Rhodamine $\mathrm{B}(\mathrm{RhB})$ in the UV-vis spectrum [50] and Fig. 6 shows the discoloration of RhB. In the absence of sodium borohydride, the reduction of dyes by AuNPs did not take place. The reduction process started spontaneously after mixing the dye solution with $\mathrm{NaBH}_{4}$ along with catalytic amounts of AuNPs and the color of the dye faded gradually. The absorption spectra of $\mathrm{RhB}\left(\lambda_{\max } 553 \mathrm{~nm}\right)$ degradation at different time intervals in the presence of AuNPs obtained from both T. conoides and S. tenerrimum are shown in Fig. 6. The reaction rates have been calculated by taking the logarithm values of absorbance $(\ln A)$ at $553 \mathrm{~nm}$ wrt time and the plots showed a good linear correlation. Inset graphs in Fig. 6 show the corresponding $\ln A$ versus time (s) plot for the same and the rate constant value for the reduction. The same procedure has been followed for the degradation studies of Sulforhodamine 101(SRh and $\lambda_{\max } 586 \mathrm{~nm}$ ). 

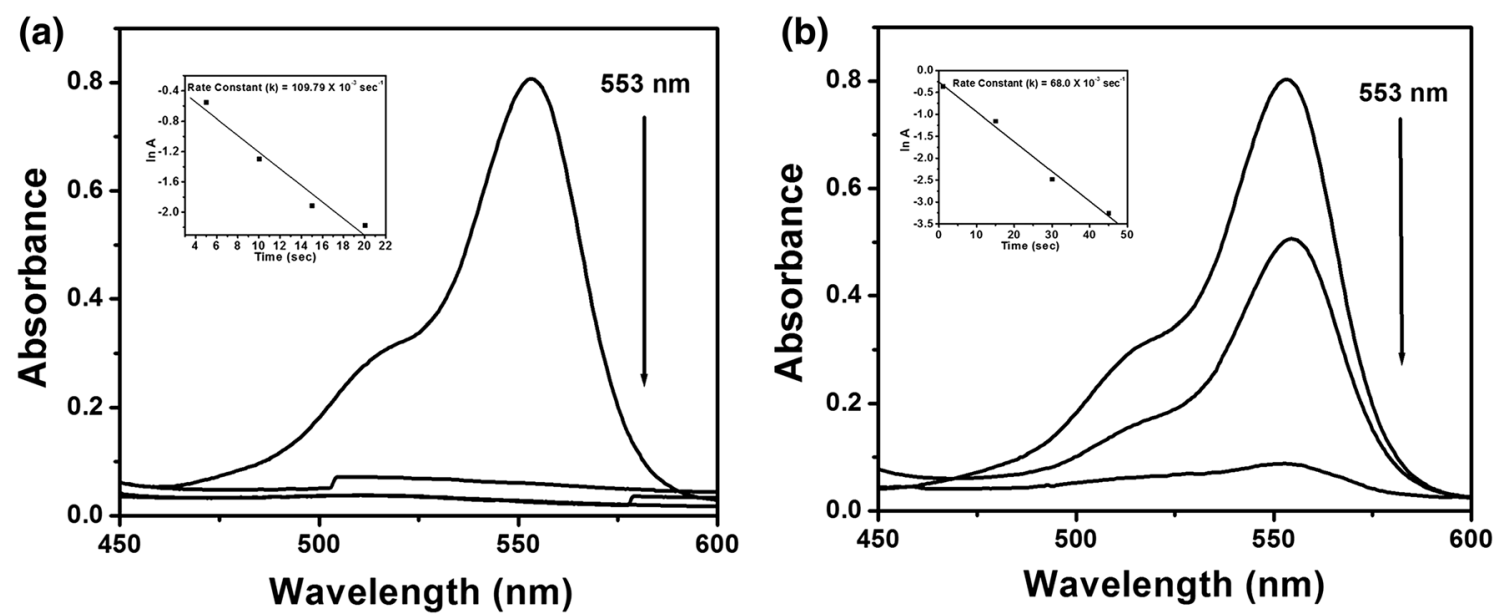

Fig. 6 UV-vis absorption spectra for catalytic reduction of Rhodamine B at $553 \mathrm{~nm}$ using AuNPs obtained from a T. conoides, b S. tenerrimum. Inset graphs are the corresponding kinetic plots $\ln A(A=$ absorbance at $553 \mathrm{~nm})$ versus time

The catalytic rates of the studied dye reductions are dependent on the nanoparticle concentration. For three catalytic runs, AuNPs concentration was varied while other conditions were kept constant. With increasing AuNP concentration, $k$ increased (Figs. 6, 7, 8, 9; Table 1) due to increase in number of reaction sites. Table 1 shows that both the reduction time as well as the $k$ values changed with varying amount of catalyst. The reaction rates are higher for $50 \mu \mathrm{l}$, medium for $25 \mu \mathrm{l}$ and lower for $10 \mu \mathrm{l}$ of catalyst added, thereby showing a dose dependency. The spectra obtained in Figs. 6, 7, 8 and 9 show that with decreasing absorbance at all wavelengths the dye molecules are getting decolorized completely without the formation of any side products. Earlier investigations reported that carboxyl, amino and hydroxyl functional groups act as efficient source for adsorbing dye molecules [51]. Results of FTIR spectra show the presence of hydroxyl, amino and carboxylate groups in the extracts as well as the synthesized gold nanoparticles. An efficient electron transfer occurs when the dye molecules are in contact with the surface of catalyst. During the reduction process, $\mathrm{NaBH}_{4}$ molecules transfer electrons to the dye molecules via the gold nanoparticles and the dye molecules get reduced to give colorless solution.

\section{Methods}

\section{Chemicals and materials}

Chloroauric acid was obtained from SRL Chemicals, India. 4-nitrophenol, p-nitroaniline, Rhodamine B and Sulforhodamine 101 were purchased from Sigma Aldrich. The two species of brown algae $S$. tenerrimum and $T$. conoides were collected from Mandapam, South Coast of Tamilnadu,
India. The algal materials were washed thoroughly with distilled water to remove debris and other associated biota. The samples were shade dried, powdered and stored at $4{ }^{\circ} \mathrm{C}$ for further use.

\section{Preparation of extracts}

The powdered sample $(1 \mathrm{~g})$ of $T$. conoides was mixed with distilled water $(20 \mathrm{ml})$, boiled for $5 \mathrm{~min}$ and filtered hot through Whatman No. 1 filter paper. The filtered extract was centrifuged at $5000 \mathrm{rpm}$ for $10 \mathrm{~min}$ and the supernatant was used both as a reducing agent and as a stabilizer for preparing gold nanoparticles. The same procedure was adopted for preparing the aqueous extract of $S$. tenerrimum. When not in use, the extracts were refrigerated and stored at $4{ }^{\circ} \mathrm{C}$.

\section{Synthesis of gold nanoparticles}

Aqueous extracts $(5 \mathrm{ml})$ of the algae were added to $1 \mathrm{mM}$ aqueous $\mathrm{AuCl}_{4}$ solution $(45 \mathrm{ml})$ in a $250-\mathrm{ml}$ Erlenmeyer flask. The flasks were kept on a magnetic stirrer at room temperature and the solutions changed to ruby red indicating the formation of gold nanoparticles. The reduction of $\mathrm{Au}^{3+}$ ions in the solution was monitored at periodic intervals with the help of UV-vis spectrophotometer (Shimadzu 2450). After the reaction reached saturation, the gold nanoparticles solution was centrifuged at 10,000 rpm (Beckman Coulter Avanti J-26SXPI) for $15 \mathrm{~min}$ and the obtained pellet was redispersed in distilled water to remove any uninteracted biomass. This process of centrifugation and redispersion was carried out twice to get a better separation of nanoparticles. The obtained nanoparticles were lyophilized using a MiniLyodel lyophilizer. 

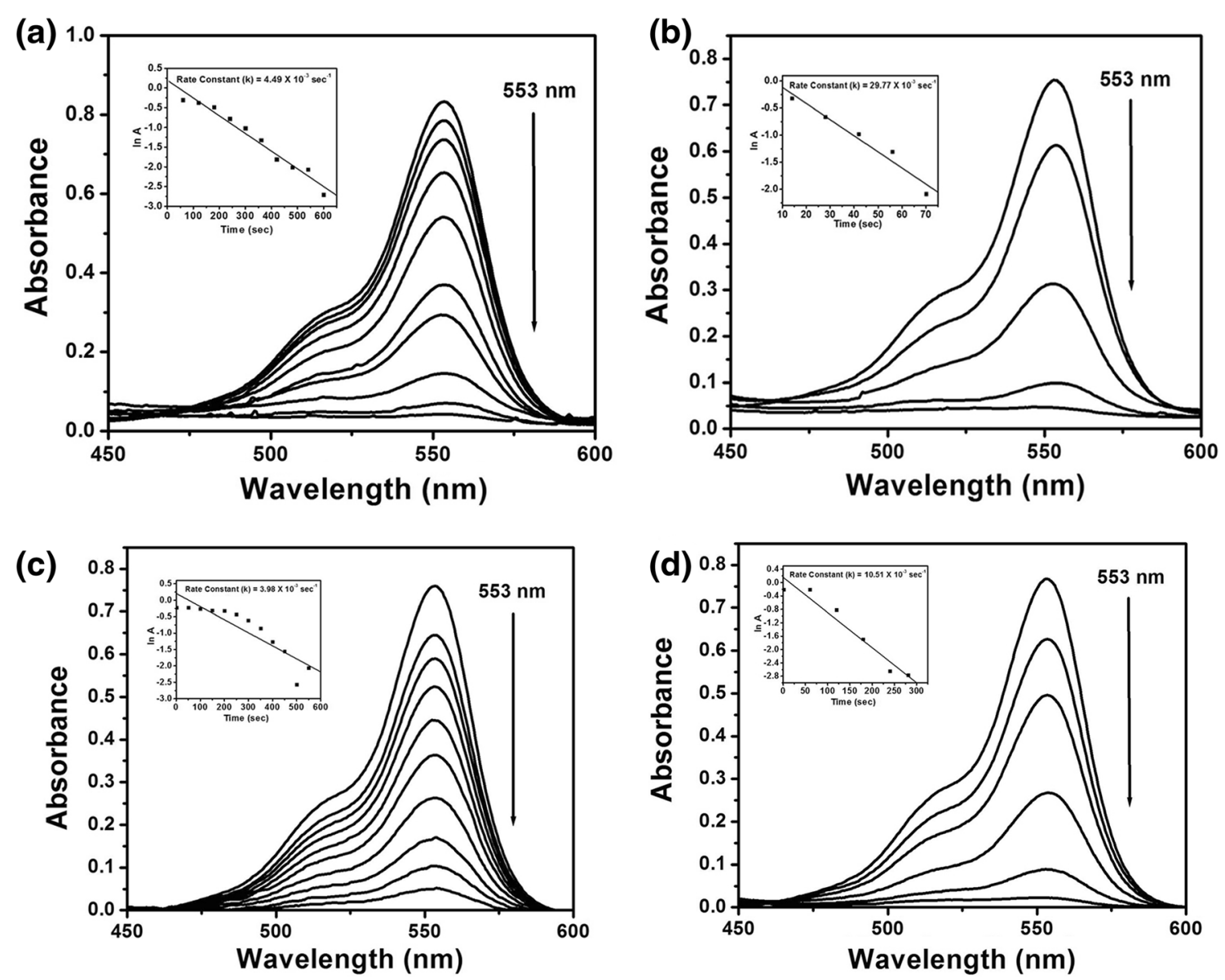

Fig. 7 UV-vis absorption spectra for catalytic reduction of Rhodamine B at $553 \mathrm{~nm}$ with $\mathrm{NaBH}_{4}$ using a $10 \mu \mathrm{l}$ of AuNPs and b $25 \mu \mathrm{l}$ of AuNPs as catalyst obtained from $T$. conoides. Below them are the successive reduction spectra of Rhodamine B catalyzed by c $10 \mu \mathrm{l}$ of

AuNPs and d $25 \mu 1$ of AuNPs obtained from S. tenerrimum. Inset graphs are the corresponding kinetic plots $\ln A(A=$ absorbance at $553 \mathrm{~nm}$ ) versus time
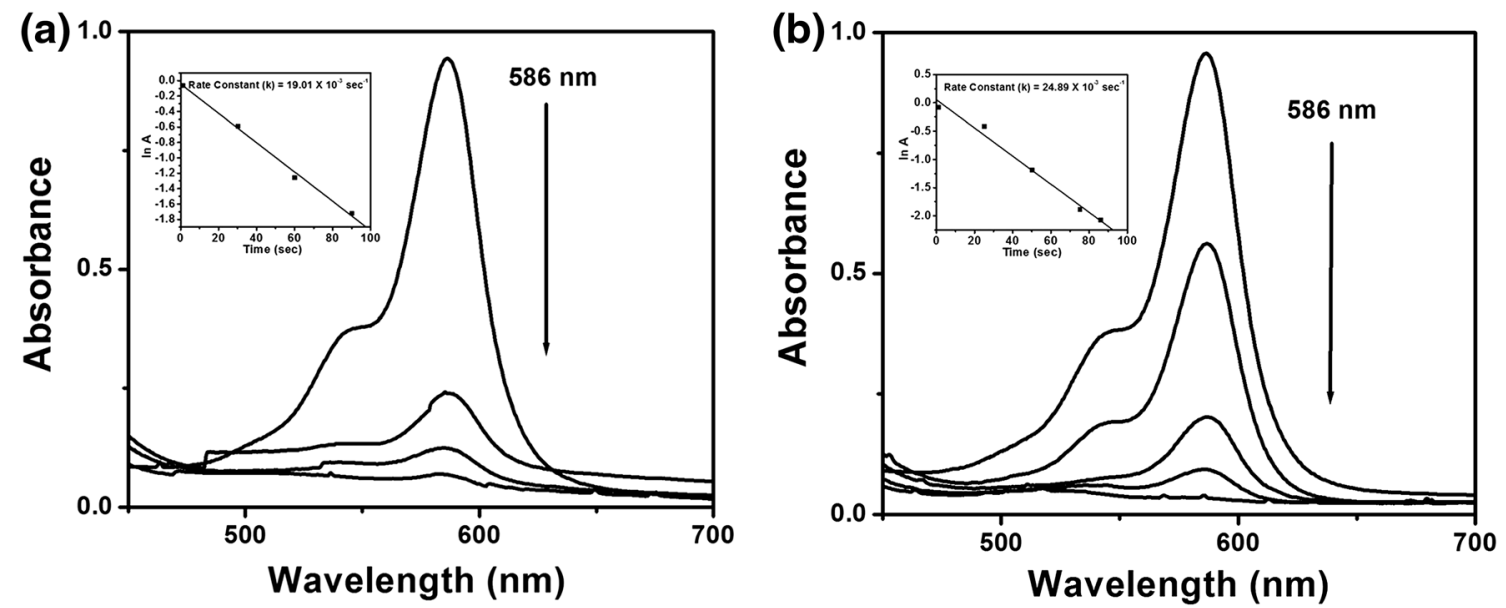

Fig. 8 UV-vis absorption spectra for catalytic reduction of Sulforhodamine 101 at $586 \mathrm{~nm}$ using AuNPs obtained from a T. conoides, b $S$. tenerrimum. Inset graphs are the corresponding kinetic plots $\ln A(A=$ absorbance at $586 \mathrm{~nm})$ versus time 

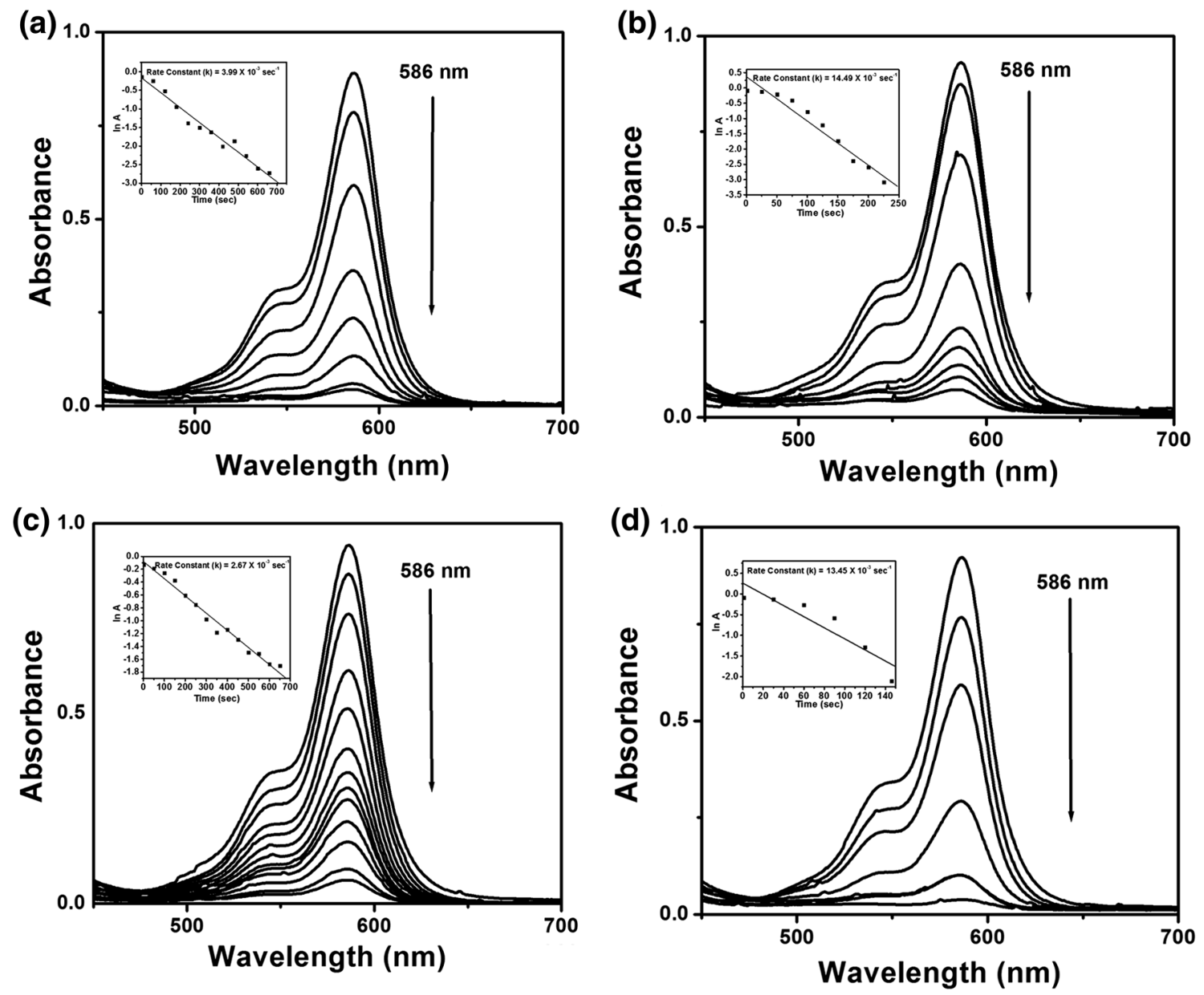

Fig. 9 The UV-vis absorption spectrum for the successive reduction of Sulforhodamine 101 at $586 \mathrm{~nm}$ with $\mathrm{NaBH}_{4}$ using a $10 \mu \mathrm{l}$ of AuNPs and b $25 \mu$ of AuNPs as catalyst obtained from T. conoides. Below them are the successive reduction spectra of Sulforhodamine

101 catalyzed by c $10 \mu \mathrm{l}$ of AuNPs and d $25 \mu \mathrm{l}$ of AuNPs obtained from $S$. tenerrimum. Inset graphs are the corresponding kinetic plots $\ln A(A=$ absorbance at $553 \mathrm{~nm})$ versus time

Table 1 The volume of AuNPs added as catalyst, reduction time and rate constant values for the reduction of dye molecules in the presence of $\mathrm{NaBH}_{4}$

\begin{tabular}{llrr}
\hline Name of the dye molecule & Volume of AuNPs added $(\mu \mathrm{l})$ & \multicolumn{2}{l}{ Rate constant $(k)\left(\mathrm{s}^{-1}\right)$ (time taken for full reduction) } \\
\cline { 3 - 4 } & & T. conoides & S. tenerrimum \\
\hline Rhodamine B & 10 & $4.49 \times 10^{-3}(600 \mathrm{~s})$ & $3.98 \times 10^{-3}(550 \mathrm{~s})$ \\
& 25 & $29.77 \times 10^{-3}(70 \mathrm{~s})$ & $10.51 \times 10^{-3}(281 \mathrm{~s})$ \\
Sulforhodamine 101 & 50 & $109.79 \times 10^{-3}(20 \mathrm{~s})$ & $68.0 \times 10^{-3}(45 \mathrm{~s})$ \\
& 10 & $3.99 \times 10^{-3}(660 \mathrm{~s})$ & $2.67 \times 10^{-3}(650 \mathrm{~s})$ \\
& 25 & $14.49 \times 10^{-3}(225 \mathrm{~s})$ & $13.45 \times 10^{-3}(146 \mathrm{~s})$ \\
& 50 & $19.01 \times 10^{-3}(90 \mathrm{~s})$ & $24.89 \times 10^{-3}(86 \mathrm{~s})$ \\
\hline
\end{tabular}

\section{Characterization studies}

The biosynthesized nanoparticles were characterized by recording the UV-vis spectra at periodic time intervals until the absorption maxima reached saturation. Millipore water was used as blank and the UV-vis spectra were recorded from 300 to $800 \mathrm{~nm}$ operated at a resolution of
$1 \mathrm{~nm}$. The spectral data were plotted using Origin 6.0 version. To obtain the particle size and shape, the gold nanoparticles solution $(1 \mu \mathrm{l})$ was placed on Formvarcoated grids, air dried and viewed at $100 \mathrm{kV}$ to carry out transmission electron microscopy (JEOL 1010 TEM using a Megaview III camera and iTEM software) studies. The nanoparticle size distribution was determined using ImageJ 
software and the resultant data were plotted in histograms. The FTIR spectra of the lyophilized powders of both the aqueous extracts and AuNPs dispersion were recorded using $\mathrm{KBr}$ pellet method with Shimadzu IRAffinity-1 spectrophotometer. The spectra were recorded in the range of $400-4000 \mathrm{~cm}^{-1}$ and with a resolution of $4 \mathrm{~cm}^{-1}$. The FTIR spectra revealed information about possible functional groups involved in the formation of AuNPs. The stability and size distribution of AuNPs were measured using DLS and zeta potential studies that were carried out using Zetasizer Nano S90 (Malvern).

\section{Evaluation of the catalytic effect of synthesized gold nanoparticles}

The catalytic decolorization reactions were carried out in a 3-ml quartz cuvette with a path length of $1 \mathrm{~cm}$ and were monitored by UV-vis spectrophotometer by following the method reported by Gangula et al. [47]. An aqueous stock solution of $p$-nitrophenol or $p$-nitroaniline $(0.3 \mathrm{ml}$ of $2 \mathrm{mM})$ was mixed with distilled water $(1.4 \mathrm{ml})$ and then an ice cold solution of sodium borohydride $(1 \mathrm{ml}$ of $0.03 \mathrm{M})$ was added. To this, the biosynthesized nanoparticles dispersion solution $(0.3 \mathrm{ml})$ was added and the contents were mixed well. The reaction progress was monitored by recording the timedependent absorption spectra in the range of $200-500 \mathrm{~nm}$ at room temperature.

The obtained nanoparticles were also used as a catalyst for the reduction of two different organic dye molecules Rhodamine B (RhB) and Sulforhodamine 101 hydrate (SRh) by following method reported by Siddhardha et al. [52]. An aqueous stock solution of RhB or SRh (2.5 ml of $10^{-5} \mathrm{M}$ ) was added to ice cold solution of sodium borohydride $(0.5 \mathrm{ml}$ of $0.1 \mathrm{M})$ and to this, nanoparticles dispersions of different volumes $(50,25$ and $10 \mu \mathrm{l})$ were added as catalyst. The mixture was shaken well and the reaction was monitored by UV-vis spectrophotometer in the range of $450-700 \mathrm{~nm}$ at room temperature.

\section{Conclusions}

The studies revealed that the aqueous extracts of brown algae (T. conoides and S. tenerrimum) can reduce $\mathrm{Au}(\mathrm{III})$ ions to gold nanoparticles (AuNPs) and also have the potential to stabilize them. The method followed for synthesis is very simple, cost-effective, efficient, non-toxic and eco-friendly. The biosynthesized AuNPs are of sizes ranging from 5 to $57 \mathrm{~nm}$. The synthesized AuNPs act as efficient catalysts for the reduction of aromatic nitro compounds and organic dye molecules. AuNPs synthesized from $T$. conoides exhibited greater catalytic potential than $S$. tenerrimum. The present biosynthesis method can be extended for preparation of other metal nanoparticles which can be explored in future for quick organic synthesis and for a wide range of catalysis reactions. According to our knowledge, this is the first report dealing with the catalytic potential of biosynthesized AuNPs from T. conoides and S. tenerrimum.

Acknowledgments The authors would like to express their gratitude to Bhagawan Sri Sathya Sai Baba, Founder Chancellor, Sri Sathya Sai Institute of Higher Learning, Puttaparthi, India for his constant support, inspiration and guidance.

\section{Compliance with ethical standards}

Conflict of interest The authors declare that they have no competing interests.

Authors' contributions MR synthesized and evaluated the catalytic efficiency of nanoparticles. DRB and RMG characterized the nanoparticles. SC helped in sample collection and identification. GNR supervised the research work. All the authors read, corrected and approved the final manuscript.

Open Access This article is distributed under the terms of the Creative Commons Attribution 4.0 International License (http://creati vecommons.org/licenses/by/4.0/), which permits unrestricted use, distribution, and reproduction in any medium, provided you give appropriate credit to the original author(s) and the source, provide a link to the Creative Commons license, and indicate if changes were made.

\section{References}

1. Dubey, S.P., Lahtinen, M., Särkkä, H., Sillanpää, M.: Bioprospective of Sorbus aucuparia leaf extract in development of silver and gold nanocolloids. Colloids Surf. B 80, 26-33 (2010)

2. Das, S., Marsili, E.: A green chemical approach for the synthesis of gold nanoparticles: characterization and mechanistic aspect. Rev. Environ. Sci. Biotechnol. 9, 199-204 (2010)

3. Edison, T.J.I., Sethuraman, M.: Instant green synthesis of silver nanoparticles using Terminalia chebula fruit extract and evaluation of their catalytic activity on reduction of methylene blue. Process Biochem. 47, 1351-1357 (2012)

4. Ghosh, S., Patil, S., Ahire, M., Kitture, R., Gurav, D.D., Jabgunde, A.M., Kale, S., Pardesi, K., Shinde, V., Bellare, J.: Gnidia glauca flower extract mediated synthesis of gold nanoparticles and evaluation of its chemocatalytic potential. J. Nanobiotechnol. 10, 17 (2012)

5. Dahl, J.A., Maddux, B.L., Hutchison, J.E.: Toward greener nanosynthesis. Chem. Rev. 107, 2228-2269 (2007)

6. Doane, T.L., Burda, C.: The unique role of nanoparticles in nanomedicine: imaging, drug delivery and therapy. Chem. Soc. Rev. 41, 2885-2911 (2012)

7. Narayanan, K.B., Sakthivel, N.: Green synthesis of biogenic metal nanoparticles by terrestrial and aquatic phototrophic and heterotrophic eukaryotes and biocompatible agents. Adv. Colloid Interface Sci. 169, 59-79 (2011)

8. Sadhasivam, S., Shanmugam, P., Veerapandian, M., Subbiah, R., Yun, K.: Biogenic synthesis of multidimensional gold nanoparticles assisted by Streptomyces hygroscopicus and its electro- 
chemical and antibacterial properties. Biometals 25, 351-360 (2012)

9. Lengke, M.F., Sanpawanitchakit, C., Southam, G.: Biosynthesis of gold nanoparticles: a review. In: Rai, M., Duran, N. (eds.) Metal nanoparticles in microbiology, pp. 37-74. Springer, Berlin (2011)

10. Dumur, F., Guerlin, A., Dumas, E., Bertin, D., Gigmes, D., Mayer, C.R.: Controlled spontaneous generation of gold nanoparticles assisted by dual reducing and capping agents. Gold Bull. 44, 119-137 (2011)

11. Inbakandan, D., Venkatesan, R., Khan, S.A.: Biosynthesis of gold nanoparticles utilizing marine sponge Acanthella elongata (Dendy, 1905). Colloids Surf. B 81, 634-639 (2010)

12. Kim, S.-K.: Handbook of Marine Macroalgae: Biotechnology and Applied Phycology. Wiley, Chichester (2011)

13. Chanda, S., Dave, R., Kaneria, M., Nagani, K.: Seaweeds: a novel, untapped source of drugs from sea to combat infectious diseases. In: Méndez-Vilas, A. (ed.) Current Research, Technology and Education Topics in Applied Microbiology and Microbial Biotechnology, pp. 473-480. Formatex Research Center, Badajoz, Spain (2010)

14. Mohamed, S., Hashim, S.N., Rahman, H.A.: Seaweeds: a sustainable functional food for complementary and alternative therapy. Trends Food Sci. Technol. 23, 83-96 (2012)

15. Swaminathan, S., Murugesan, S., Damodarkumar, S., Dhamotharan, R., Bhuvaneshwari, S.: Synthesis and characterization of gold nanoparticles from alga Acanthophora spicifera (VAHL) Boergesen. Int. J. Nanosci. Nanotechnol. 2, 85-94 (2011)

16. Oza, G., Pandey, S., Mewada, A., Kalita, G., Sharon, M., Phata, J., Ambernath, W., Sharon, M.: Facile biosynthesis of gold nanoparticles exploiting optimum $\mathrm{pH}$ and temperature of fresh water algae Chlorella pyrenoidusa. Adv. Appl. Sci. Res. 3, 1405-1412 (2012)

17. Rajasulochana, P., Krishnamoorthy, P., Dhamotharan, R.: Potential application of Kappaphycus alvarezii in agricultural and pharmaceutical industry. J. Chem. Pharm. Res. 4, 33-37 (2012)

18. Singaravelu, G., Arockiamary, J., Kumar, V.G., Govindaraju, K.: A novel extracellular synthesis of monodisperse gold nanoparticles using marine alga, Sargassum wightii Greville. Colloids Surf. B 57, 97-101 (2007)

19. Dhas, T.S., Kumar, V.G., Abraham, L.S., Karthick, V., Govindaraju, K.: Sargassum myriocystum mediated biosynthesis of gold nanoparticles. Spectrochim. Acta, Part A 99, 97-101 (2012)

20. Rajathi, F.A.A., Parthiban, C., Kumar, V.G., Anantharaman, P.: Biosynthesis of antibacterial gold nanoparticles using brown alga, Stoechospermum marginatum (Kützing). Spectrochim. Acta, Part A 99, 166-173 (2012)

21. Ghodake, G., Lee, D.S.: Biological synthesis of gold nanoparticles using the aqueous extract of the brown algae Laminaria japonica. J. Nanoelectron. Optoelectron. 6, 268-271 (2011)

22. Orendorff, C.J., Sau, T.K., Murphy, C.J.: Shape-dependent plasmon-resonant gold nanoparticles. Small 2, 636-639 (2006)

23. Wong, Y., Yu, J.: Laccase-catalyzed decolorization of synthetic dyes. Water Res. 33, 3512-3520 (1999)

24. Banat, I.M., Nigam, P., Singh, D., Marchant, R.: Microbial decolorization of textile-dye containing effluents: a review. Bioresour. Technol. 58, 217-227 (1996)

25. Srinivasan, A., Viraraghavan, T.: Decolorization of dye wastewaters by biosorbents: a review. J. Environ. Manag. 91, 1915-1929 (2010)

26. MubarakAli, D., Thajuddin, N., Jeganathan, K., Gunasekaran, M.: Plant extract mediated synthesis of silver and gold nanoparticles and its antibacterial activity against clinically isolated pathogens. Colloids Surf. B 85, 360-365 (2011)

27. Mata, Y., Torres, E., Blazquez, M., Ballester, A., González, F., Munoz, J.: Gold (III) biosorption and bioreduction with the brown alga Fucus vesiculosus. J. Hazard. Mater. 166, 612-618 (2009)

28. Vijayaraghavan, K., Mahadevan, A., Sathishkumar, M., Pavagadhi, S., Balasubramanian, R.: Biosynthesis of $\mathrm{Au}$ (0) from $\mathrm{Au}(\mathrm{III})$ via biosorption and bioreduction using brown marine alga Turbinaria conoides. Chem. Eng. J. 167, 223-227 (2011)

29. Li, B., Lu, F., Wei, X., Zhao, R.: Fucoidan: structure and bioactivity. Molecules 13, 1671-1695 (2008)

30. Chattopadhyay, N., Ghosh, T., Sinha, S., Chattopadhyay, K., Karmakar, P., Ray, B.: Polysaccharides from Turbinaria conoides: structural features and antioxidant capacity. Food Chem. 118, 823-829 (2010)

31. Sinha, S., Astani, A., Ghosh, T., Schnitzler, P., Ray, B. Polysaccharides from Sargassum tenerrimum: structural features, chemical modification and anti-viral activity. Phytochemistry $\mathbf{7 1}$ 235-242 (2010)

32. Nellore, J., Pauline, P.C., Amarnath, K.: Biogenic synthesis by Sphearanthus amaranthoids; towards the efficient production of the biocompatible gold nanoparticles. Dig. J. Nanomater. Biostruct. 7, 123-133 (2012)

33. Bakshi, M.S., Sachar, S., Kaur, G., Bhandari, P., Kaur, G., Biesinger, M.C., Possmayer, F., Petersen, N.O.: Dependence of crystal growth of gold nanoparticles on the capping behavior of surfactant at ambient conditions. Cryst. Growth Des. 8, 1713-1719 (2008)

34. Shankar, S.S., Ahmad, A., Pasricha, R., Sastry, M.: Bioreduction of chloroaurate ions by geranium leaves and its endophytic fungus yields gold nanoparticles of different shapes. J. Mater. Chem. 13, 1822-1826 (2003)

35. Treguer-Delapierre, M., Majimel, J., Mornet, S., Duguet, E., Ravaine, S.: Synthesis of non-spherical gold nanoparticles. Gold Bull. 41, 195-207 (2008)

36. Chandini, S.K., Ganesan, P., Bhaskar, N.: In vitro antioxidant activities of three selected brown seaweeds of India. Food Chem. 107, 707-713 (2008)

37. Devi, G.K., Manivannan, K., Thirumaran, G., Rajathi, F.A.A., Anantharaman, P.: In vitro antioxidant activities of selected seaweeds from Southeast coast of India. Asian Pac. J. Trop. Med. 4, 205-211 (2011)

38. Sokhi, G., Vijayaraghavan, M.: Extracellular polysaccharides in Turbinaria conoides-structure and ultrastructure. Curr. Sci. 54, 1192-1193 (1985)

39. Vijayaraghavan, K., Sathishkumar, M., Balasubramanian, R.: Biosorption of lanthanum, cerium, europium, and ytterbium by a brown marine alga, Turbinaria conoides. Ind. Eng. Chem. Res. 49, 4405-4411 (2010)

40. Rajeshkumar, S., Malarkodi, C., Gnanajobitha, G., Paulkumar, K., Vanaja, M., Kannan, C., Annadurai, G.: Seaweed-mediated synthesis of gold nanoparticles using Turbinaria conoides and its characterization. J. Nanostruc. Chem. 3, 1-7 (2013)

41. Kumar, P., Senthamil Selvi, S., Lakshmi Prabha, A., Prem Kumar, K., Ganeshkumar, R., Govindaraju, M.: Synthesis of silver nanoparticles from Sargassum tenerrimum and screening phytochemicals for its antibacterial activity. Nano Biomed. Eng. 4, 12-16 (2012)

42. Arivuselvan, N., Radhiga, M., Anantharaman, P.: In vitro antioxidant and anticoagulant activities of sulphated polysaccharides from brown seaweed (Turbinaria ornata) (Turner) J. Agardh. Asian J. Pharm. Biol. Res. 1, 232-238 (2011)

43. Aravindhan, R., Madhan, B., Rao, J.R., Nair, B.U., Ramasami, T.: Bioaccumulation of chromium from tannery wastewater: an approach for chrome recovery and reuse. Environ. Sci. Technol. 38, 300-306 (2004)

44. Mohankumar, K., Meenakshi, S., Balasubramanian, T., Manivasagam, T.: Sulfated polysaccharides of Turbinaria conoides dose-dependently mitigate oxidative stress by ameliorating 
antioxidants in isoproterenol induced myocardial injured rats: evidence from histopathological study. Egypt. Heart J. 64, 147-153 (2012)

45. Lee, K.Y., Hwang, J., Lee, Y.W., Kim, J., Han, S.W.: One-step synthesis of gold nanoparticles using azacryptand and their applications in SERS and catalysis. J. Colloid Interface Sci. 316, 476-481 (2007)

46. Chen, L.-J., Ma, H., Chen, K., Cha, H.-R., Lee, Y.-I., Qian, D.-J., Hao, J., Liu, H.-G.: Synthesis and assembly of gold nanoparticledoped polymer solid foam films at the liquid/liquid interface and their catalytic properties. J. Colloid Interface Sci. 362, 81-88 (2011)

47. Gangula, A., Podila, R., Ramakrishna, M., Karanam, L., Janardhana, C., Rao, A.M.: Catalytic reduction of 4-nitrophenol using biogenic gold and silver nanoparticles derived from Breynia rhamnoides. Langmuir 27, 15268-15274 (2011)

48. Esumi, K., Isono, R., Yoshimura, T.: Preparation of PAMAM-and PPI-metal (silver, platinum, and palladium) nanocomposites and their catalytic activities for reduction of 4-nitrophenol. Langmuir 20, 237-243 (2004)
49. Bai, X., Gao, Y., Liu, H.-G., Zheng, L.: Synthesis of amphiphilic ionic liquids terminated gold nanorods and their superior catalytic activity for the reduction of nitro compounds. J. Phys. Chem. C 113, 17730-17736 (2009)

50. Chen, Y., Yin, R.-H., Wu, Q.-S.: Solvothermal synthesis of welldisperse $\mathrm{ZnS}$ nanorods with efficient photocatalytic properties. J. Nanomater. 2012, 34 (2012)

51. Das, S.K., Ghosh, P., Ghosh, I., Guha, A.K.: Adsorption of rhodamine B on Rhizopus oryzae: role of functional groups and cell wall components. Colloids Surf. B 65, 30-34 (2008)

52. Siddhardha, R.S., Kumar, V.L., Kaniyoor, A., Muthukumar, V.S., Ramaprabhu, S., Podila, R., Rao, A., Ramamurthy, S.S.: Synthesis and characterization of gold graphene composite with dyes as model substrates for decolorization: a surfactant free laser ablation approach. Spectrochim. Acta, Part A 133, 365-371 (2014) 